Braz J Med Biol Res, December 2011, Volume 44(12) 1261-1268

doi: 10.1590/S0100-879X2011007500137

The response of social anxiety disorder patients to threat scenarios differs from that of healthy controls

S.C.V. Mesquita, R. Shuhama, F.L. Osório, J.A.S. Crippa, S.R. Loureiro, J. Landeira-Fernandez, F.G. Graeff and C.M. Del-Ben

The Brazilian Journal of Medical and Biological Research is partially financed by

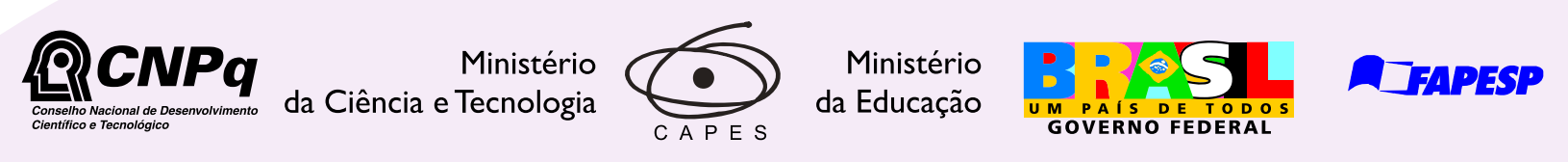

Institutional Sponsors
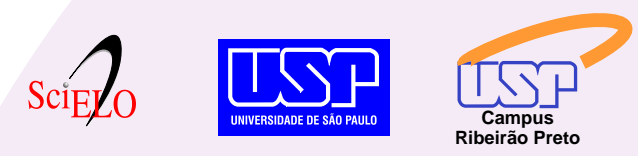

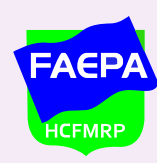

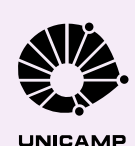

UNICAMP
Ф SHIMADZU

Explore High - Performance MS Orbitrap Technology In Proteomics \& Metabolomics

analitica Thermo 


\title{
The response of social anxiety disorder patients to threat scenarios differs from that of healthy controls
}

\author{
S.C.V. Mesquita ${ }^{1}$, R. Shuhama ${ }^{1}$, F.L. Osório ${ }^{1,3}$, J.A.S. Crippa ${ }^{1,3}$, S.R. Loureiro1,3, \\ J. Landeira-Fernandez², F.G. Graeff ${ }^{1}$ and C.M. Del-Ben ${ }^{1}$ \\ 1Departamento de Neurociências e Ciências do Comportamento, \\ Faculdade de Medicina de Ribeirão Preto, Universidade de São Paulo, Ribeirão Preto, SP, Brasil \\ ${ }^{2}$ Departamento de Psicologia, Pontifícia Universidade Católica do Rio de Janeiro e \\ Universidade Estácio de Sá, Rio de Janeiro, RJ, Brasil \\ 3 Instituto Nacional de Ciência e Tecnologia Translacional em Medicina, CNPq, Brasil
}

\begin{abstract}
The objective of the present study was to evaluate the response of social anxiety disorder (SAD) patients to threat scenarios. First-choice responses to 12 scenarios describing conspecific threatening situations and mean scores of defensive direction and defensive intensity dimensions were compared between 87 SAD patients free of medication and 87 matched healthy controls ( $\mathrm{HC})$. A significant gender difference in the first-choice responses was identified for seven scenarios among $\mathrm{HCs}$ but only for two scenarios among SAD patients. A significantly higher proportion of SAD patients chose "freezing" in response to "Bush" and "Noise" scenarios, whereas the most frequent response by HCs to these scenarios was "check out". SAD males chose "run away" and "yell" more often than healthy men in response to the scenarios "Park" and "Elevator", respectively. There was a positive correlation between the severity of symptoms and both defensive direction and defensive intensity dimensions. Factorial analysis confirmed the gradient of defensive reactions derived from animal studies. SAD patients chose more urgent defensive responses to threat scenarios, seeming to perceive them as more dangerous than HCs and tending to move away from the source of threat. This is consistent with the hypothesis that the physiopathology of anxiety disorders involves brain structures responsible for defensive behaviors.
\end{abstract}

Key words: Social anxiety disorder; Defensive response; Threat scenarios

\section{Introduction}

Animal studies have provided substantial evidence for a complex and hierarchical set of defensive behaviors in response to threatening situations, which are processed by different brain structures. According to studies with wild mice carried out by Caroline and Robert Blanchard (1), the choice of the most appropriate defensive strategy for each threat depends mainly on the distance from the threat, the magnitude and ambiguity of the threat, and the availability of an escape route and/or a place for hiding. Briefly, in the presence of a clear threat situation, albeit still at a certain distance from the threat, the animal will choose to flee if a route of flight is available. In the absence of the possibility of flight, another option would be freezing. As the distance from the threat decreases, the alternative would be defen- sive threat and, as an ultimate possibility, defensive attack. On the other hand, a potential threat would be associated with risk-assessment behavior.

From an evolutionary perspective, humans have maintained the same neural structures and behavioral repertoire against threats as those observed in other mammals. Along this line of thought, Deakin and Graeff (2) have argued that risk-assessment behavior, elicited by a potential threat, is related to anxiety, escape from and avoidance of a distal threat is related to fear, and flight reaction to a proximal threat is related to panic. Later, McNaughton and Corr (3) expanded this idea by adding defensive direction, resulting in a two-dimensional (distance and direction) model of defense. They argued that an approach-defensive system

Correspondence: R. Shuhama, Departamento de Neurociências e Ciências do Comportamento, Faculdade de Medicina de Ribeirão Preto, USP, Avenida Bandeirantes, 3900, 14048-900 Ribeirão Preto, SP, Brasil. Fax: +55-16-3602-2544. E-mail: rshuhama@ig.com.br

Received June 7, 2011. Accepted October 4, 2011. Available online October 21, 2011. Published November $28,2011$. 
deals with a potential threat and approach-avoidance conflict, which is related to anxiety, and that an avoidancedefensive system commands withdrawal from proximal threats, which is related to fear and panic. These dimensional systems are longitudinally distributed along the brain, with the former largely represented in the forebrain and the latter in the hindbrain. This model makes a clear distinction between anxiety and fear/panic. The former is related to moving toward the threat and involves risk-assessment behavior or behavioral inhibition, whereas the latter implies moving away from the threat stimulus and includes avoidance, escape and flight behaviors.

According to these models, the categorical behaviors and neural substrates involved in the pathophysiology of anxiety disorders are distinct (2-4). Panic disorder and specific phobias are due to abnormalities in the functioning of the avoidancedefensive system, the former involving the periaqueductal gray, with the correlated behaviors of exploding or freezing, and the latter involving the medial hypothalamus and the amygdala, with the correlated behaviors of escape and avoidance. On the other hand, generalized anxiety disorder is a consequence of alterations in the defensive-approach system; the amygdala and the septo-hippocampal system are the main brain structures involved in the behavioral categories of arousal/startle and cognitive abnormalities, respectively. In this hierarchical model, complex anxiety, such as social anxiety, is placed at the top of the defensive-approach system, and dorsal prefrontal areas, among other structures, are the main brain substrate of this process.

The extrapolation of findings on defensive behavior from animal studies to humans is not a simple task due to ethical and even operational limitations. An indirect approach to this issue in experiments involving human subjects is the use of scenarios, in which the individual is encouraged to imagine a particular situation and to try to predict what would be his/ her most likely behavioral response to that situation. In light of this, a questionnaire composed by a set of threat scenarios designed to vary along the five dimensions known to influence animal defensive behavior has been developed (5). In this study carried out in Hawaii with healthy volunteers, the majority of the predictions derived from the animal literature were confirmed, suggesting congruence between human and non-human defensive systems. These results have been largely replicated by our group in Brazil (6) and in another study (7) conducted in the United Kingdom, showing that individuals with personality traits reflecting high anxiety have a tendency to face a threat, while those with high traits of fear are more prone to run away from a threat.

To our knowledge, no study using threat scenarios with patients with anxiety disorders has been carried out to date. In the present study, we have chosen to evaluate patients with social anxiety disorder (SAD), because this is one of the most common anxiety disorders in the general population, with a lifetime prevalence ranging from 5.0 to $13.3 \%$ (8). The essential feature of SAD is anxiety in social situations, in which individuals feel that they are being watched by people outside their family environment and fear the resulting negative evaluations. This suggests that SAD patients have a dysfunction of brain systems responsible for assessing the risks and benefits of social aggregation (9), which may be probed by the above questionnaire, which consists of scenarios in which threat is represented by another human being. Therefore, the objective of the present study was to evaluate the response of SAD patients to threatening scenarios. We hypothesized that, in comparison to controls, SAD patients would show more urgent responses to the scenarios due to overvaluation of the danger of the situations depicted in the scenarios.

\section{Material and Methods}

\section{Participants}

The sample consisted of 174 participants aged 17 to 35 years $($ mean $=20.98 \pm 2.69)$ who were students recruited from the local university community, with at least 11 years of formal education.

Participants were initially selected on the basis of screening instruments for SAD, as described elsewhere $(10,11)$. The Structured Clinical Interview from the DSM-IV, clinical version (SCID-CV) (12), translated into Portuguese $(13,14)$, was administered for the confirmation of the diagnosis of SAD. Participants who presented other psychiatric disorders were excluded, except for those with past depressive episodes because depression is frequently comorbid with SAD. Healthy controls (HC) were also assessed by the SCID-CV in an effort to exclude those with a psychiatric diagnosis. In both groups, participants with a history of psychoactive drug abuse, with the exception of nicotine, and of clinical medical conditions were excluded.

The study was approved by the local Research Ethics Committee from the Hospital das Clínicas de Ribeirão Preto, São Paulo University, and written informed consent was obtained from each participant. Professional treatment in the public health system was offered to all the volunteers identified with SAD.

\section{Psychological measures}

Clinical assessment. The presence and severity of anxious and phobic symptoms were assessed by three different instruments, all of them translated into and adapted to Portuguese: the BeckAnxiety Inventory $(\mathrm{BAI})(15,16)$ and the Social Phobia Inventory (SPIN) $(10,17)$, both self-report instruments, and the Brief Social Phobia Scale (BSPS) $(11,18)$, a heteroadministered instrument.

Defensive behavior. The Brazilian version of the 12 scenarios for the assessment of defensive behavior (6) was adapted from the original questionnaire (5) and administered to all participants. This is a self-report instrument that presents script-scenarios describing conspecific threat situations, as described in Table 1.

In response to each scenario, each participant was asked to choose one of 10 alternative defensive behaviors that he/ she believed would be his/her behavioral response to that 
situation. The possible response choices were: hide (protect oneself behind something, lock the doors); freeze, stand still (paralyzed with fear); flee, try to escape (run away, drive fast, climb a tree); threaten to scream or call for help; yell, scream or ask for help (calling the police or somebody); threaten to attack; attack or fight (punch, kick, shove); investigate to see if the danger is real (observe carefully, get closer, check out); look for something to use as a weapon (a stick, a knife, a gun); apologize, negotiate or beg for mercy.

\section{Procedure}

Data collection was part of an integrated study, as previously mentioned $(10,11)$. Briefly, self-administered screening instruments (BAI and SPIN) were applied collectively following school activities to a total of 2314 undergraduate students aged 17 to 35 years. Of this initial group, 473 possible SAD cases were contacted by telephone and responded to the $F$ module of the SCID-IV. The 88 participants identified as SAD cases as well as 90 healthy volunteers were invited to a face-to-face clinical interview for confirmation of the diagnosis of SAD or the absence of a psychiatric diagnosis, in the case of the controls, when the SCID-CV, the BSPS and the threatening scenarios were applied.

\section{Statistical analysis}

Data were analyzed using the Statistical Package for the Social Sciences, 16th version for Windows. Categorical variables were assessed by the Fisher exact test and numeri- cal variables by the Student $t$-test. The defensive behavioral responses that amounted to less than $10 \%$ of the total choices were collapsed under a general category named "other". For each scenario, the proportions of first-choice responses were compared between groups (SAD and HC). Taking into account previous studies that have reported significant differences between genders regarding defensive behaviors $(5,6)$, this variable was included in the analysis. The alpha value was set at 0.05 . All tests of statistical significance were two-sided. With the aim to compare our data with previous results, we used the coding scheme proposed by Perkins and Corr (7) to code the responses to the scenarios. According to this coding scheme, Defensive Direction (DD) and Defensive Intensity (DI) Scores can be obtained by assigning numerical values to each response. The scores consisted of the sum of all the responses to the 12 scenarios, which were coded as: "run away" and "hide" = 2.0; "freeze" = 1.5; remaining responses = 1.0 for the DD score, and as: "attack" and "yell" = 3.0; "freeze", "run away" and "hide" = 2.0; remaining responses $=1.0$ for the DI score. Pearson's correlations were applied to examine the associations between severity of symptoms (SPIN and BSPS scales) and defensive reactions.

The effect size and statistical power (SP) are also provided for group comparisons. The criteria used to estimate the effect size for the numerical data were Cohen's $d \geq 0.8$ (large), $0.5 \leq \mathrm{d}<0.8$ (medium) and $0.2 \leq \mathrm{d}<0.5$ (small) (19). In order to interpret the Cramer's $\vee$ for the nominal data, the criteria used were $>0.9$ (perfect), $0.7<\mathrm{V} \leq 0.9$ (strong), 0.7

Table 1. Script-scenarios describing conspecific threat situations.

\begin{tabular}{|c|c|}
\hline Bush & $\begin{array}{l}\text { You are walking alone in a familiar, albeit isolated, place when a rough-looking stranger comes out from behind } \\
\text { a tree to attack you }\end{array}$ \\
\hline Elevator & $\begin{array}{l}\text { Late at night, you are alone in an elevator. When it stops and the doors open, a rough-looking stranger enters } \\
\text { quickly to attack you, blocking your exit }\end{array}$ \\
\hline Stoplight & $\begin{array}{l}\text { You are driving home alone in your car. While you are stopped at a light, an irritated stranger starts to beat on } \\
\text { the window of your car, insulting and threatening you }\end{array}$ \\
\hline Tailgating & $\begin{array}{l}\text { Driving along a two-way street, you see in your rearview mirror that a car is dangerously close to yours. The } \\
\text { driver cannot overtake you and starts to hit the horn, coming dangerously close to the back of your car }\end{array}$ \\
\hline Corner & $\begin{array}{l}\text { Late at night you are walking in an unknown place. While turning a corner, you accidentally bump into a man. } \\
\text { He becomes furious and pushes you }\end{array}$ \\
\hline Acquaintance & $\begin{array}{l}\text { You are in an empty place; talking to somebody you do not know very well. Without an apparent motive, he/she } \\
\text { starts to elbow and push you. You are not sure if he/she (same gender as you) is doing this seriously or is just } \\
\text { playing with you }\end{array}$ \\
\hline Park & $\begin{array}{l}\text { Late at night, you are in a square when you see a rough-looking stranger about ten meters from you holding a } \\
\text { knife. It is obvious that he plans to attack you }\end{array}$ \\
\hline Grab & $\begin{array}{l}\text { Late at night, you are leaving an empty building by yourself, far from any other structures. As soon as you are } \\
\text { outside, you feel a hand grasping your arm }\end{array}$ \\
\hline Noise & $\begin{array}{l}\text { Late at night, it is dark and you are sleeping alone in your bed. You suddenly wake up feeling that you heard a } \\
\text { suspicious noise }\end{array}$ \\
\hline Phone & $\begin{array}{l}\text { Late at night, you are home alone preparing to go to bed when the telephone rings. You pick it up but do not } \\
\text { recognize the voice of the person, who does not identify himself but tells you that he is in front of your house } \\
\text { and then hangs up }\end{array}$ \\
\hline Whisper & $\begin{array}{l}\text { You are alone reading a book when you hear noises in front of your house. You cannot distinguish them well, } \\
\text { but when you listen with more attention, it seems to be the sound of people whispering }\end{array}$ \\
\hline Steps & You are walking alone in a dark and empty place when you hear steps just behind you \\
\hline
\end{tabular}


$<\mathrm{V} \leq 0.4$ (moderate) and $0.4<\mathrm{V} \leq 0.1$ (small) (20).

We also included a factor analysis of the responses to the scenarios. It has been pointed out that factor analysis can be employed to evaluate the interconnections and underlying structure of a set of variables measured on a nominal scale (21). Therefore, factor analysis was employed to identify clustering among the 12 scenarios. Before performing the factor analysis, the Kaiser-Meyer-Olkin (KMO) measure was calculated to evaluate sampling adequacy. It has been suggested that $\mathrm{KMO}$ values should be equal to or above 0.60 to perform and interpret satisfactorily a factor analysis solution. Principal factor analysis is the preferable method for factor extraction when employed in an exploratory manner (20). Because the present study was the first attempt to explore relationships among the 12 scenarios, factors were extracted by principal factor analysis. Factor loadings equal to or higher than 0.5 were generally considered to be very satisfactory. Varimax factor rotation was performed to determine the extent to which the 12 scenarios would cluster together. To determine the number of factors to retain in conducting the Varimax factor rotation, Kaiser's criterion (eigenvalue-greater-than-one rule) (22) was employed

\section{Results}

\section{Clinical features}

The demographic and clinical characteristics of the total sample are summarized in Table 2. As expected, SAD patients showed significantly higher means on the severity scales than $\mathrm{HC}$ (BAI, $\mathrm{t}=14.30, \mathrm{P}<0.001$; SPIN, $t=12.71, P<0.001 ;$ BSPS, $t=14.19, P<0.001) . S A D$ patients presented a mean duration of the disorder of 9.96
$(S D=4.23)$ years, with a mean age of onset of 10.96 (SD $=4.15$ ) years. Approximately half of them were diagnosed as having a generalized subtype $(50.6 \%)$. The majority of the patients were classified as having moderately severe SAD (71.3\%), and fear of public speaking was prevalent in the sample (92.0\%). More importantly, almost all SAD patients $(93.1 \%)$ had not been previously diagnosed and were free of medication at the time of data collection. There were no significant differences between genders with regard to clinical features.

\section{First-choice responses to the scenarios}

Table 3 shows that the 12 scenarios did elicit different

Table 2. Characteristics of the sample.

\begin{tabular}{lcc}
\hline & SAD patients & Healthy controls \\
\hline Number & 87 & 87 \\
Gender & $51 \mathrm{~F} / 36 \mathrm{M}$ & $51 \mathrm{~F} / 36 \mathrm{M}$ \\
Age (years) & $21.01 \pm 2.60$ & $20.94 \pm 2.78$ \\
SPIN & $34.48 \pm 13.06^{*}$ & $10.52 \pm 11.77$ \\
BSPS & $32.41 \pm 10.70^{*}$ & $10.66 \pm 9.22$ \\
BAI & $18.78 \pm 11.90^{*}$ & $8.63 \pm 8.49$ \\
DD & $16.61 \pm 2.32^{*}$ & $15.45 \pm 2.15$ \\
DI & $19.61 \pm 3.98$ & $18.48 \pm 3.90$ \\
\hline
\end{tabular}

Data are reported as means $\pm S D$. SAD = social anxiety disorder; $\mathrm{F}=$ female; $\mathrm{M}=$ male; SPIN = Social Phobia Inventory; BSPS = Brief Social Phobia Scale; BAI = Beck's Anxiety Inventory; DD = Defensive Direction Score; DI = Defensive Intensity Score. ${ }^{*} \mathrm{P}<$ 0.05 compared to controls (Student $t$-test).

Table 3. First-choice response rate to each scenario made by SAD patients and gender- and age-matched healthy controls.

\begin{tabular}{|c|c|c|c|c|c|c|c|c|c|c|c|c|}
\hline \multirow[t]{3}{*}{ Scenario } & \multicolumn{6}{|c|}{ Healthy controls } & \multicolumn{6}{|c|}{ SAD patients } \\
\hline & \multicolumn{2}{|c|}{ Female $(\mathrm{N}=51)$} & \multicolumn{2}{|c|}{ Male $(\mathrm{N}=36)$} & \multirow[t]{2}{*}{$x^{2}$} & \multirow[t]{2}{*}{$P$} & \multicolumn{2}{|c|}{ Female $(\mathrm{N}=51)$} & \multicolumn{2}{|c|}{ Male $(\mathrm{N}=36)$} & \multirow[t]{2}{*}{$x^{2}$} & \multirow[t]{2}{*}{$P$} \\
\hline & Behavior & $\%$ & Behavior & $\%$ & & & Behavior & $\%$ & Behavior & $\%$ & & \\
\hline Bush & Run away & 52.9 & Check out & 36.1 & 23.67 & $<0.001$ & Run away & 52.9 & Run away & 41.7 & 6.31 & NS \\
\hline Elevator & Yell & 35.3 & Attack & 30.6 & 22.31 & $<0.001$ & Yell & 19.6 & Check out & 19.4 & 8.14 & NS \\
\hline Stoplight & Run away & 86.3 & Run away & 52.8 & 11.85 & 0.001 & Run away & 70.6 & Run away & 50.0 & 3.79 & NS \\
\hline Tailgating & Run away & 49.0 & Others & 55.6 & 6.53 & NS & Run away & 52.9 & Run away & 50.0 & 3.93 & NS \\
\hline Corner & Apologize & 51.0 & Apologize & 57.5 & 4.99 & NS & Apologize & 51.0 & Apologize & 52.8 & 1.82 & NS \\
\hline Acquaintance & Check out & 51.0 & Check out & 61.1 & 1.28 & NS & Check out & 37.3 & Check out & 55.6 & 2.80 & NS \\
\hline Park & Run away & 64.7 & Run away & 50.0 & 12.69 & 0.002 & Run away & 58.8 & Run away & 77.8 & 7.29 & 0.026 \\
\hline Grab & Yell & 35.3 & Check out & 50.0 & 19.24 & 0.001 & Yell & 23.5 & Check out & 27.8 & 5.26 & NS \\
\hline Noise & Check out & 52.9 & Check out & 77.8 & 6.42 & 0.004 & Check out & 37.3 & Check out & 63.9 & 6.56 & 0.038 \\
\hline Phone & Check out & 43.1 & Check out & 66.7 & 4.49 & NS & Check out & 29.4 & Check out & 50.0 & 5.36 & NS \\
\hline Whisper & Check out & 60.8 & Check out & 75.0 & 1.92 & NS & Check out & 51.0 & Check out & 72.2 & 4.04 & NS \\
\hline Step & Run away & 47.1 & Check out & 50.0 & 3.54 & NS & Run away & 49.0 & Check out & 44.4 & 2.66 & NS \\
\hline
\end{tabular}

SAD = social anxiety disorder. NS = not significant. The Fisher exact test was used for statistical analysis. 
first-choice responses. Among healthy controls, a significant gender difference in first-choice responses was found in seven scenarios. In the scenarios Stoplight, Park and Noise, the first option was the same for both genders; the first option was 'run away' for the Stoplight and Park scenarios and 'check out' for the Noise scenario, but with a significant difference in the response rate. In the scenarios Bush, Elevator, Tailgating, and Grab, there were differences between males and females in the behavior chosen as the first option. 'Run away' was the first choice of females for the scenarios Bush and Tailgating, whereas males chose 'check out' and 'others' for the two scenarios, respectively. In response to the scenarios Elevator and Grab, healthy women picked 'yell' as their first option of response, and men selected 'attack' for the former and 'check out' for the latter.

Among SAD patients, significant gender differences were observed only in the Park and Noise scenarios. In the Whisper scenario, a gender difference almost reached significance $(P=0.051)$, with a higher proportion of males choosing 'check out'.

\section{Previous experience}

Previous experiences with situations similar to those described in each scenario varied across scenarios, but significant differences in the choice of the most probable response were found only in the Stoplight and Tailgating scenarios. In both scenarios, the difference was due to a higher proportion of individuals with previous experience choosing 'run away'.

\section{Comparison between diagnosis groups}

A significant difference between groups was found in two scenarios: Bush $\left(X^{2}=14.57, P=0.005\right.$; $S P=0.41$, Cramer's $V=0.29)$ and Noise $\left(X^{2}=7.19, P=0.026\right.$; SP $=0.43$, Cramer's $V=0.20)$. As can be seen in Figure 1, in both scenarios, these differences were due to a higher proportion of SAD patients choosing 'freezing' (Bush, $\mathrm{P}=$ 0.018; Noise, $P=0.016$ ), and a higher proportion of healthy controls choosing 'check out' (Bush, $\mathrm{P}=0.018$; Noise, $\mathrm{P}=$ 0.067 ) as their first option.

Because a significant difference was found in the Stoplight and Tailgating scenarios due to previous experiences, the responses of each group to these scenarios were analyzed, controlling for previous experience. No significant difference in the first-choice response was found.

With respect to the gender of the participants, no significant difference between healthy female controls and female SAD patients was found. However, significant differences were found between male participants in the Park scenario $\left(X^{2}=6.28, P=0.026\right.$; $S P=0.74$, Cramer's $\left.V=0.30\right)$, with SAD males choosing a more urgent behavior, 'run away', more frequently than healthy males. There was also a trend toward significance in the Elevator scenario $\left(X^{2}=7.98, P=\right.$ 0.088 ; SP $=0.54$, Cramer's $V=0.33$ ) due to a significant proportion of SAD male patients $(P=0.024)$ choosing 'yell', whereas the primary option of healthy males was mainly 'attack'. These data are presented in Figure 2.

With regard to the defensive scores, female participants showed higher scores than male participants, independent of the diagnosis, in both dimensions [DD $(t=4.44, P<0.001$; $S P=0.10$, Cohen's $d=0.78) ; \mathrm{DI}(t=5.26, P<0.001 ; S P$
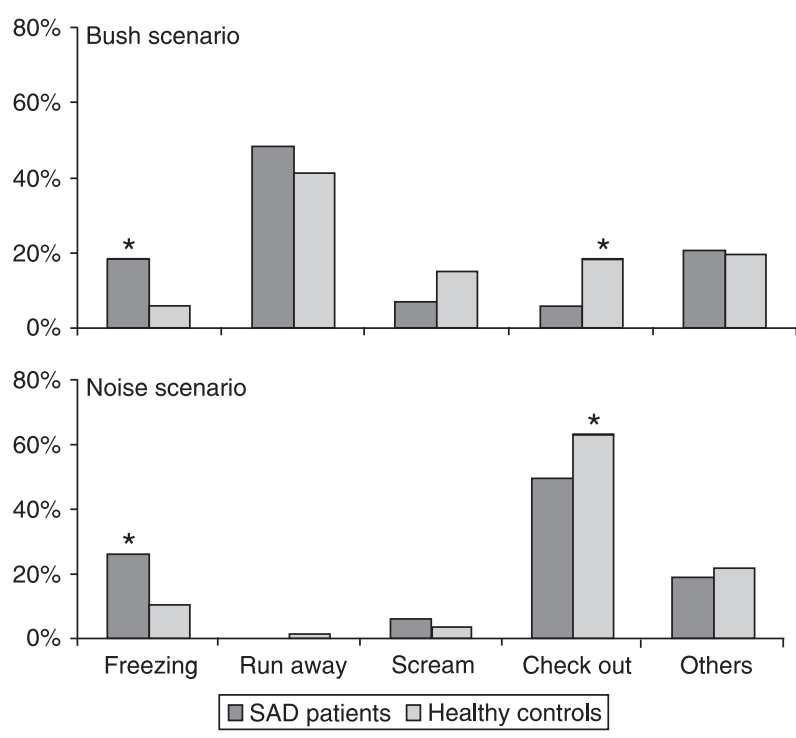

Figure 1. Frequency of first-choice responses to the Bush and Noise scenarios by SAD patients of both genders $(\mathrm{N}=87)$ and matched healthy controls $(N=87)$. SAD = social anxiety disorder. *Significant differences between groups $(P<0.05$, Fisher exact test).
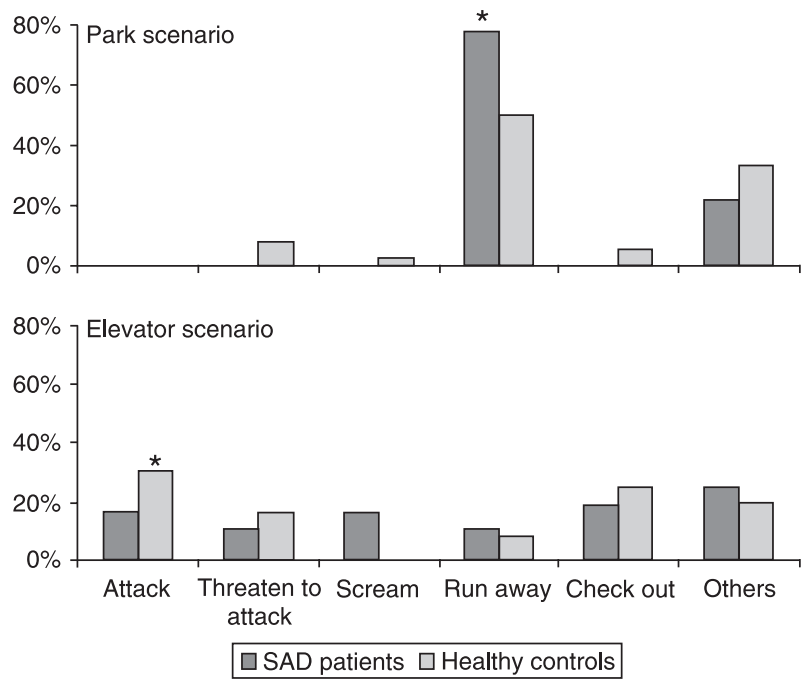

Figure 2. Frequency of first-choice responses to the Park and Elevator scenarios by SAD male patients $(\mathrm{N}=36)$ and matched healthy controls $(N=36)$. SAD = social anxiety disorder. *Significant differences between groups $(P<0.05$, Fisher exact test). 
$=0.14$, Cohen's $d=0.83)$ ]. As can be seen in Table 2, SAD patients were more prone to move away from threats [DD ( $t$ $=2.24, P=0.027, S P=0.03$, Cohen's $d=1.23)]$ and tended to perceive threats as more intense [DI $(t=1.88, P=0.061$, $\mathrm{SP}=0.02$, Cohen's $\mathrm{d}=1.17)$ ] than $\mathrm{HC}$. There was a positive correlation between the severity of phobic symptoms (SPIN and BSPS scales) and both the defensive direction dimension $(r=0.28, P<0.001 ; r=0.32, P<0.001$, respectively) and the defensive intensity dimension $(r=0.27, P<0.001 ; r=0.28, P$ $<0.001$, respectively). There was also a significant correlation between the two defensive dimensions $(r=0.67, P<0.001)$.

We also carried out an analysis excluding the six SAD volunteers who had a previous psychiatric diagnosis and the significant differences between patients and controls in the scenarios Bush $\left(X^{2}=6.08, P=0.186\right.$; Cramer's $V=0.284$ ) and Noise $\left(X^{2}=6.94, P=0.031\right.$; Cramer's $\left.V=0.296\right)$ remained.

\section{Factor analysis}

The $\mathrm{KMO}$ analysis revealed a value of 0.75 , indicating that the correlation matrix was suitable for factor analysis. Kaiser's criterion led to a four-factor solution, which accounted for $55.2 \%$ of the variance. Table 4 depicts the pattern of rotated factor loadings for the four-factor solution. As a whole, the four-factor solution presented a well-defined structure. All 12 scenarios had salient factor loadings exclusively on a single factor, and no hyperplanes (i.e., scenarios that did not have salient loadings on any factor) were found. The first factor was responsible for $24.4 \%$ of the variance, with an eigenvalue of 2.93 . The second factor explained $12.3 \%$ of the variance, with an eigenvalue of 1.42 . The third factor explained $9.8 \%$ of the variance, with an eigenvalue of 1.18 . Finally, the fourth factor explained $7.6 \%$ of the variance, with an eigenvalue of 1.37 .

\section{Discussion}

The aim of the present study was to verify the repertoire of defensive responses, assessed by threat scenarios of different levels of intensity, distance, ambiguity, possibility of escape and/or hiding, of patients with a diagnosis of SAD. To our knowledge, this is the first study to indicate that persons with a diagnosis of anxiety disorder process threat stimuli/situations differently than do healthy controls, which is in agreement with the experimentally derived hypothesis that implicates neural defense mechanisms in the physiopathology of anxiety disorders (2-4). Because the great majority of patients included in this study had not been previously diagnosed or treated, the present results were not influenced by medications and likely reflect inherent characteristics of the disorder itself.

The clinical profile of the SAD patients included in this study, which described a generalized subtype and the fear of public speaking as the most common feared situation, is in accordance with epidemiologic studies in the community (23) and with university students (24). The moderate severity of
Table 4. Principal axis factor analysis and factor analysis loading following Varimax rotation.

\begin{tabular}{lllll}
\hline Scenario & \multicolumn{4}{c}{ Factor } \\
\cline { 2 - 5 } & 1 & 2 & 3 & 4 \\
\hline Park & 0.71 & & & \\
Stoplight & 0.66 & & & \\
Elevator & 0.65 & & & \\
Bush & 0.55 & & & \\
Grab & & 0.66 & & \\
Step & & 0.66 & & \\
Noise & & 0.60 & & \\
Phone & & & 0.66 & \\
Corner & & & 0.64 & \\
Tailgating & & & 0.61 & \\
Acquaintance & & & & 0.82 \\
Whisper & & & & 0.77 \\
\hline
\end{tabular}

Factor loadings smaller than 0.5 are not shown.

the symptoms and an average time of untreated symptoms of about 10 years also correspond with the observation that people with SAD do not always seek treatment (25). Despite their long history of symptoms, this group of SAD participants had reached higher educational levels, although it was not possible to evaluate the difficulties experienced by them.

The profile of the responses to the scenarios chosen by the healthy volunteers included in this study was very similar to that of the original study (5) and the validation study, in which the threat scenarios were adapted to the Brazilian population (6). In comparison to our previous results, the most frequent first-choice response of healthy male volunteers was the same for 11 scenarios, and, among healthy women, there was agreement for 10 scenarios. In the present study, the first-choice response of healthy men to the Bush scenario was "check out", and, in the previous study, it was "run away". In the Tailgating and Grab scenarios, the first-choice responses of healthy women were "run away" and "yelling", respectively, whereas in the former study they were "other" and "freezing", respectively. These apparent inconsistencies may be related to differences in the inclusion and exclusion criteria of the samples of the two studies because, in the former study, the occurrence of a psychiatric diagnosis was not systematically investigated, as done in the present study. Therefore, we can speculate that, in the previous study, more anxious participants were included in the sample, which led to a higher proportion of more urgent responses to the threat scenarios.

We also confirmed differences between genders in three scenarios (Elevator, Stoplight and Grab), as previously described (6), and we found gender differences in four additional scenarios (Bush, Tailgating, Park, and Noise). It is important to emphasize that the difference between genders 
was confirmed in just two scenarios (Noise and Park) among SAD patients. The results obtained in the Park scenario are particularly interesting because the first-choice response "run away" was more frequent among healthy women than among healthy men but more frequent among SAD male patients than among SAD female patients. Observational studies with primates suggest that females tend to move away from sources of danger, probably due to their physical vulnerability and lower ability to fight compared to males (26). This is in agreement with the results obtained with healthy volunteers, but the reason for a shift in an opposite direction among the SAD patients is unclear.

With regard to the influence of previous experience on the responses, the results obtained in the present study also agree with those reported in our previous study (6). Participants with previous experience in the situations described in the Stoplight and Tailgating scenarios tended to choose more urgent responses more often than those without previous experience.

The main result obtained in the present study concerned the difference between SAD patients and healthy volunteers in their responses to two scenarios, independently of the volunteers' gender. SAD patients tended to choose a more urgent response, "freezing", in comparison to $\mathrm{HC}$, who chose "check out", in the Bush and Noise scenarios. This suggests that SAD patients interpreted the threat situations described in these scenarios as more dangerous than healthy controls. Similarly, male SAD patients chose "run away" as their primary response to the Park scenario more often than healthy volunteers and "yell" in response to the Elevator scenario, which otherwise was more common in females. Taken together, these data point to a higher vulnerability of SAD patients to social situations perceived as dangerous, as indicated by hypersensitivity to threat stimuli leading to maladaptive responses.

Along the same lines, SAD patients had higher scores for defensive direction and defensive intensity scores compared to controls, which is in agreement with previous data showing that fear-prone persons tend to select responses that move them away from the source of threat, probably because they have a magnified perception of threat relative to less fear-prone persons $(27,28)$. The propensity to move away from a threat and to perceive it as more intense seems to be related to the severity of the phobic symptoms because a significant, albeit weak-to-moderate, correlation between defensive scores and clinical rating scales specific for SAD was found here. On the other hand, the correlation between the two dimensions was also significant and qualitatively robust, which is in agreement with McNaughton and Corr's (3) proposition that the two dimensions collapse when a threat is perceived as particularly intense (i.e., at high intensity levels of perceived threat, the fear prevails).

Factor analysis points to an organization of the threat scenarios into four dimensions. The first factor includes four scenarios - Elevator, Stoplight, Bush, and Park - that represent unambiguous threats with high intensity and short distance and with features associated with responses to a proximal threat in animal studies (5). It is also noteworthy that all four scenarios have a component in their description of a "rough-looking" or "irritated" stranger who takes an explicitly aggressive approach, representing an immediate physical threat. This analysis was corroborated by the fact that the most frequent response given by the participants evaluated in this study was "run away", although the most frequent response of male SAD patients to the Elevator scenario was the unintuitive "check out". The latter finding reinforces the hypothesis of a maladaptive defensive response in SAD patients. The second factor grouped three scenarios - Grab, Step and Noise - sharing intermediate levels of intensity, uncertainty of the threatening situation, and moderate-to-low possibility of flight. The third factor included three scenarios of potential threat of moderate ambiguity - Phone, Corner, Tailgating - that required high levels of alert and vigilance and yet were paired with a reasonable chance of escape. These are characteristics of threats that elicit risk-assessment behavior in animal studies (5). Finally, the fourth factor included the two scenarios - Whisper and Acquaintance - with the lowest level of intensity and highest chance of escape. Thus, factorial analysis confirmed the gradient of defensive reactions derived from animal studies.

The results obtained in this study should be viewed with caution because we were not assessing the actual defensive behavior but rather the beliefs of the participants regarding how they would react in situations represented in the scenarios. Still, it is believed that the use of script-driven scenarios may give an approximate, acute estimation of behavioral trends because humans respond emotionally to symbolic stimuli and memory imagery $(28,29)$.

This study has some limitations worthy of note. The sample consisted only of young adults (university students) and the statistical power was small for some measures; thus, the results cannot be generalized to other populations. However, this fact allowed the assessment of subjects selected from a homogenous community, who were not undergoing any specific treatment, which led to a better balance of age, gender, educational and socioeconomic levels. Moreover, the study considered DSM-IV axis I comorbidities only and did not characterize the premorbid psychiatric history of the subjects.

In summary, we have shown that SAD patients tend to choose more urgent defensive responses to threat scenarios, perceiving them as more dangerous than healthy volunteers and tending to move away from the source of threat. These data are in agreement with the hypothesis that the physiopathology of anxiety disorders may involve brain structures responsible for defensive behavior. Future investigations will benefit from the controlled inclusion of SAD patients under treatment so that the potential effects of medication and psychotherapy, which are known to lead to symptom improvement, on responses to threat scenarios can be evaluated. 


\section{References}

1. Blanchard DC, Griebel G, Blanchard RJ. Mouse defensive behaviors: pharmacological and behavioral assays for anxiety and panic. Neurosci Biobehav Rev 2001; 25: 205-218.

2. Deakin JFW, Graeff FG. 5-HT and mechanisms of defense. J Psychopharmacol 1991; 5: 305-315.

3. McNaughton N, Corr PJ. A two-dimensional neuropsychology of defense: fear/anxiety and defensive distance. Neurosci Biobehav Rev 2004; 28: 285-305.

4. Gray J, McNaugton N. The neuropsychology of anxiety: an enquiry into the functions of the septo-hippocampal system. 2nd edn. Oxford: Oxford University Press; 2000.

5. Blanchard DC, Hynd AL, Minke KA, Minemoto T, Blanchard RJ. Human defensive behaviors to threat scenarios show parallels to fear- and anxiety-related defense patterns of non-human mammals. Neurosci Biobehav Rev 2001; 25: 761-770.

6. Shuhama R, Del-Ben CM, Loureiro SR, Graeff FG. Defensive responses to threat scenarios in Brazilians reproduce the pattern of Hawaiian Americans and non-human mammals. Braz J Med Biol Res 2008; 41: 324-332.

7. Perkins AM, Corr PJ. Reactions to threat and personality: psychometric differentiation of intensity and direction dimensions of human defensive behaviour. Behav Brain Res 2006; 169: 21-28.

8. Kessler RC, McGonagle KA, Zhao S, Nelson CB, Hughes $M$, Eshleman S, et al. Lifetime and 12-month prevalence of DSM-III-R psychiatric disorders in the United States. Results from the National Comorbidity Survey. Arch Gen Psychiatry 1994; 51: 8-19.

9. Stein MB. Neurobiological perspectives on social phobia: from affiliation to zoology. Biol Psychiatry 1998; 44: 1277 1285.

10. Osorio FL, Crippa JA, Loureiro SR. Evaluation of the psychometric properties of the Social Phobia Inventory in university students. Compr Psychiatry 2010; 51: 630-640.

11. Osorio FL, Crippa JA, Loureiro SR. Study of the psychometric qualities of the Brief Social Phobia Scale (BSPS) in Brazilian university students. Eur Psychiatry 2010; 25: 178188.

12. First MB, Spitzer RL, Gibbon M, Williams JBW. Structured clinical interview for DSM-IV-TR Axis I disorders, clinical version (SCID-CV). New York: Biometrics Research, New York State Psychiatric Institute; 1997.

13. Del-Ben CM, Vilela JAA, Crippa JAS, Hallak JEC, Labate CM, Zuardi AW. Confiabilidade Teste-Reteste da Entrevista Clínica Estruturada para o DSM-IV - Versão Clínica (SCID-
CV) Traduzida para o Português. Rev Bras Psiquiatr 2001; 23: 156-159.

14. Del-Ben CM, Hallak JE, Sponholz A Jr, Marques JM, Labate $\mathrm{CM}$, Contel JO, et al. Accuracy of psychiatric diagnosis performed under indirect supervision. Rev Bras Psiquiatr 2005; 27: 58-62.

15. Beck AT, Epstein N, Brown G, Steer RA. An inventory for measuring clinical anxiety: psychometric properties. J Consult Clin Psychol 1988; 56: 893-897.

16. Cunha JA. Manual da versão em português das Escalas Beck. São Paulo: Casa do Psicólogo; 2001.

17. Connor KM, Davidson JR, Churchill LE, Sherwood A, Foa E, Weisler RH. Psychometric properties of the Social Phobia Inventory (SPIN). New self-rating scale. $\mathrm{Br} J$ Psychiatry 2000; 176: 379-386.

18. Davidson JR, Miner CM, De Veaugh-Geiss J, Tupler LA, Colket JT, Potts NL. The Brief Social Phobia Scale: a psychometric evaluation. Psychol Med 1997; 27: 161-166.

19. Cohen J. Statistical power for behavioral sciences. New York: Academic Press; 1988.

20. Field A. Discovering statistics using SPSS. London: Sage; 2005.

21. Rummel R. Applied factor analysis. Evanston: Northwestern University Press; 1988.

22. Kaiser HF. An index of factor simplicity. Psychometrik 1974; 39: 6.

23. Furmark T. Social phobia: overview of community surveys. Acta Psychiatr Scand 2002; 105: 84-93.

24. Tillfors M, Furmark T. Social phobia in Swedish university students: prevalence, subgroups and avoidant behavior. Soc Psychiatry Psychiatr Epidemiol 2007; 42: 79-86.

25. Lader $M$. The clinical relevance of treating social phobia. $J$ Affect Disord 1998; 50 (Suppl 1): S29-S34.

26. Wrangham R, Peterson D. Demonic males. Apes and the origins of human violence. New York: Houghton Mifflin Company; 1996.

27. Perkins AM, Cooper A, Abdelall M, Smillie LD, Corr PJ. Personality and defensive reactions: fear, trait anxiety, and threat magnification. J Pers 2010; 78: 1071-1090.

28. Lang PJ, Davis M, Ohman A. Fear and anxiety: animal models and human cognitive psychophysiology. J Affect Disord 2000; 61: 137-159.

29. Lang PJ, Greenwald MK, Bradley MM, Hamm AO. Looking at pictures: affective, facial, visceral, and behavioral reactions. Psychophysiology 1993; 30: 261-273. 